\title{
BURJUVAZININ VE KAPITALIST ZIHNIYETIN TEMELLERI
}

\section{Cem TUTAR*}

Tutar, C. (2019). "Burjuvazinin ve Kapitalist Zihniyetin Temelleri". Etkileşim. 4. 314-319.

Werner Sombart'ın Burjuva: Modern Ekonomi Dönemine Ait Insanın Ahlaki ve Entelektüel Tarihine Katkı ${ }^{1}$ isimli eseri, 2008 yılının Mart ayında Doğu Batı Yayınları'ndan çıkmıştır. 404 sayfalık kitap, 2 ana kitaptan oluşmaktadır. ilk kitap kapitalist zihniyetin gelişme sürecine, ikinci kitap ise kapitalist zihniyetin oluşmasını sağlayan unsurlara odaklanmıştır. 'Önsöz' ve 'Giriş' bölümlerini takip eden bu iki ana kitabı birbiriyle ilişkili 7 bölüm, 'Sonuç' ve 'Dizin' izlemektedir.

Alman iktisat tarihçisi ve sosyolog olan Sombart 20. yüzyılın başlangıcında Kıta Avrupası'nın önde gelen sosyal bilimcilerinden biridir. illk dönem eserlerinde Marksizm'in etkisi gözlemlenirken giderek Marksizm karşıtı bir çizgiye yönelmiştir. Sınıfları ve toplumların evrimlerini inceleyen yapıtlarında kapitalizmin doğuşunu ve gelişim sürecinde hangi etkenlerin olduğunu ortaya koymaya çalışmıştır. Sombart, iktisadi faaliyeti sadece insanların yaşamlarını sürdürmeleri için gerekli olan ekonomik faaliyetlerle tanımlamamakta, aynı zamanda buradaki ahlaki ve düşünsel öğelere odaklanarak kapitalizmin ruhunu da dikkate almaktadır. Türkçe yayınlanan eserleri arasında Dünya Görüşü Bilim ve Ekonomi (2004), Aşk, Lüks ve Kapitalizm (2014), Yahudiler ve Modern Kapitalizm (2016) bulunmaktadır.

'Giriş' bölümünde kitabın konusu, amacı ve metodolojisi üzerinde durulmaktadır. Ekonomik yaşam kendisini oluşturan örgütlenmeler ve dış çevre ile biçimsel bir yapıya sahiptir. Ekonomik yaşama eleştirel bir perspektiften yak-

1 Almanca özgün metin Der Bourgeois: zur Geistesgeschichte des modernen Wirtschaftsmenschen olup Oğuz Adanır tarafından çeviride kullanılan Fransızca metin Les Bourgeois: Contribution a l'Histoire Morale et Intellectuelle'dir. Kitabın eleştirisinde bu metinden yararlanılmıştır.

* Doktor Öğretim Üyesi, Üsküdar Üniversitesi, İletişim Fakültesi, cem.tutar@uskudar.edu.tr, Orcid: 0000-0002-4547-6171 
laşan Sombart, her dönemin ekonomik yaşamını belirleyen düşünce biçiminin değiştiğini vurgulamaktadır. Kısaca "ekonomik yaşamın tinsel unsurları" olarak adlandırılan kuramında Sombart, kapitalizm ve burjuva öncesi ekonomiyi harcama ekonomisi olarak adlandırmaktadır. Gereksinimler ile sınırlı bir dünyada iki toplumsal kesim öne çıkmaktadır: efendiler ve halk. Bu dönemin insanın temel özelliği daha çok duygusal yapıya sahip, entelektüel açıdan pek gelişmemiş, zihinsel bir enerji ve disiplinden yoksun bir varlık iken, diğeri de irade yetersizliği olarak adlandırılabilecek bir niteliğe sahip olmasıdır. Buna göre dönemin insan tipi çalışmaları gereken kadar çalışırken bunun dışındaki zamanlarını eğlence ve dinlemeye ayırmaktadır. Geleneksel toplum yapısının ve alışkanlığının olduğu bu toplumsal örgütlenmede bireyin amacı yenilik peşinde olmaktan çok, var olan toplumun işleyişini daha kusursuz hale getirmeye çalışmaktır. Yazar kitabın iki temel amacı olduğunu vurgulamaktadır. Bunlardan ilki başlangıçtan günümüze, hatta geleceğe kapitalist zihniyetin gelişimini göstermek diğeri ise kapitalist zihniyeti doğuran ve gelişmesine yol açan nedenleri ve yeni toplumsal koşulların sistematik olarak ortaya konulmasıdır. Buna göre burjuva zihniyeti kapitalist zihniyete can veren bir saik olarak öne çıkmaktadır.

Girişin ardından gelen birinci kitap "Kapitalist Zihniyetin Gelişme Süreci" adını taşımaktadır ve dört bölümden oluşmaktadır. "Girişimcilik Anlayışı/Ruhu" adını taşıyan birinci bölümde Sombart, Germenlerin altına olan düşkünlüğünü vurgulayarak 12. yüzyıl sonuna kadar hazine biriktirme tutkusunun Avrupa'da egemen olduğunu belirtmektedir. 12. yüzyıl sonuyla değerleri madenlerin ödeme aracı paraya dönüştürüldüğü görülmektedir. 15 ve 16. yüzyılda Batı Avrupa'da egemen olan bu süreç, 17. ve 18. yüzyılda da devam etmiştir. Böylece para modern insan ruhunun ayrılmaz bir parçası haline gelmiştir. Sombart, geniş anlamda "aynı ve tek bir iradeye boyun eğen birçok insan arasında süreklilik taşıyan bir iş birliğinin uzun vadede gerçekleştirilmesini" girişim olarak adlandırmaktadır (2017: 70). Girişimcinin aynı zamanda bir fatih, bir örgütleyici ve bir müzakereci olması gerektiğini savunan yazar ilk girişimcilik biçimlerini ${ }^{2}$ açıkladıktan sonra, kazanç tutkusu ile girişimcilik ruhu arasındaki ilişkileri ortaya koyarak kapitalist şirketlerin nasıl ortaya çıktığını göstermeye çalışmıştır. Bu bağlamda belli başlı kapitalist girişimcilik çeşitlerine ${ }^{3}$ değinerek bu bölümü tamamlamıştır.

ilk bölümü takip eden üç bölümde, burjuva-kapitalist zihniyetin temel olarak birbiriyle ilişki içerisinde olan temel özelliklerine değinerek farklı uluslardaki görünümlerine de yer vermekte ve eski moda burjuva ile modern ekonomi insanı arasındaki farklara değinmektedir. Sombart burada özet olarak burjuvayı toplumsal bir sınıfın temsilcisi olarak görmektense onu bir insan tipi

2 ilk girişimcilik biçimleri askeri seferler, büyük toprak mülkiyeti yani senyörlük, devlet ve kilise olarak sıralanabilir.

${ }^{3}$ Korsan/hırsız, feodal beyler, devlet memurları, spekülatörler, tüccarlar ve zanaatkârlar, kapitalist girişimciliğin örnekleri olarak öne çıkmaktadır. Ayrıntılı bilgi için bkz: (2017: 87-125).

ISSN: 2636-7955 | Yıl2|Sayı 4| Ekim 2019 | ETKíleşim | 315 
olarak tanımlamaktadır. 13. yüzyılda Floransa'da ortaya çıkan bu insan tipi kendisinden önceki 'senyör tipi' yaşam biçimi ile taban tabana zıt bir dönüşümden söz etmektedir. Bunlardan ilkine göre harcama ekonomisi önemliyken, ikincisinde hayatın her alanında denge kavramını yaşamının merkezine yerleştirilmektedir. Düzenin sürdürülmesi yönündeki temel saik, iş ahlakı ve hesap kitap bu dönemin insanın temel özellikleri olarak öne çıkmaktadır. Yazar kapitalist zihniyetin ulusal görünümlerine odaklanırken aslında ekonomik faaliyet sürecine etki eden kültürel ve zihinsel pratiklerin etkisini açık olarak ortaya koymaktadır. ${ }^{4}$ Böylece ekonomik etkinliğin dünyanın her yerinde gereksinimlerin karşılanması üzerine evrensel bir modeli olmadığı toplumlar ve kültürler arasında sosyolojik bir bakış açısıyla önemli farkların olduğunu ortaya çıkarmaya çalışmaktadır. Kapitalist zihniyetin günümüzde aldığı şekli anlayabilmek için tarih içerisinde belgeler ile bu zihinsel yapının izini süren Sombart, kapitalizmin başlangıcından 18. yüzyıla kadar eski moda burjuva dönemi olduğunu belirtmektedir. Bu insan tipi modern ekonomi insanından farklı bilişsel güdülere sahiptir. İdealist bir tutumla insan yaşamına hizmet etmek, makine yerine insana öncelik vermek ve reklamın olmaması öne çıkan özelliklerdir. Oysa 19. yüzyıl sonunda durum değişerek modern ekonomide insan farklı̈zelliklere sahip olmaktadır. Bunlar arasında insanın ikinci plana düşmesi, müzakere, spekülasyon ve hesaplamanın öneminin artması, akılcılık ekseninde ekonomik davranışın örgütlenmesi ve tutumluluk, dürüstlük gibi eski dönemin burjuva değerlerinin kişisel bir nitelik olmaktan çıkması sayılabilir.

íkinci kitap "Kapitalist Zihniyetin Oluşmasını Sağlayan Unsurlar" adını taşımakta ve üç bölümden oluşmaktadır. Yazarın bu bölümdeki odak noktası kapitalist zihniyetin kaynaklarını basit bir tarihsel yayılma ve yaygınlaşma olayı olarak görmeyip bu zihniyetin nasıl ortaya çıktığının araştırmasıdır. Bu bağlamda Sombart, kapitalist zihniyetin kapitalizmin doğal bir sonucu olarak görmenin dogmatik bir bakış açısı olduğunu söyleyip eleştirmektedir. Yazar ilk olarak kapitalist zihniyet oluşumunda biyolojik özellikleri incelemektedir. Bu açıdan bakıldığında burjuvanın kalbinin iki ruhtan oluştuğunu öne sürmektedir. ilki girişimci ikincisi ise burjuva olarak nitelendirilebilecek ruh. Bu ikisinin birlikteliği, kapitalist zihniyetin oluşmasına yol açmaktadır. Burjuva mizacı olarak adlandırılan bu özelliğin hangi halklarda daha çok olduğunu araştıran Sombart, buna göre ülkeleri tasnif etmiştir. ${ }^{5}$ Sombart ikinci olarak ahlaki özel-

\footnotetext{
${ }^{4}$ italya kapitalist zihniyetin ilk ortaya çıkıp yaygınlaştığı ülkedir ancak 16. yüzyıl ile birlikte girişimcilik ruhunda bir gevşeme ve senyör tipi yaşama geçiş ile gerileme yaşanmıştır. Hollanda 17. yüzyılda bu zihniyetin en kusursuz örneği olan ülke iken Fransa'da üç nedenden ötürü kapitalist zihniyet gelişmemiştir: senyör tipi yaşama öykünme, düzenli bir işe sahip olma (memurluk) çılıınlığı ve ticaretin küçümsenmesi, Temmuz Monarşisine kadar ticaret ve sanayinin saygın bir yere sahip olmadığı görülmektedir. Ayrıntılı bilgi için bkz.: (2017: 154-176).
}

5 Etnik özelliklere göre yapılan sınıflamada ortalama altı kapitalist özellikler taşıyan halklar arasında ilk sırada Keltler, Gotlar ve bazı Germen aşiretleri vardır. Keltler soylu yaşam 
liklere odaklanırken bu bölümde felsefe, dini etkilerin ve ahlaki özelliklerin kapitalist zihniyetin oluşmasındaki etkilerine odaklanmaktadır. Felsefi anlamda yararcılık ve akılcılık bu alanı beslerken dini açıdan ise öncelikle 14. yüzyıldan itibaren resmi Katolik mezhebine egemen olan Tommasoculuk ${ }^{6}$ öğretisi kapitalist zihniyetin oluşumuna etki etmiştir. Bu açıdan bakıldığında kapitalizmin gelişim sürecinde genelde referans verilen Max Weber'in "Protestan Ahlakı ve Kapitalizmin Ruhu" adlı eserinden farklı olarak Sombart kapitalist zihniyetin temellerinin Protestanlık mezhebinde değil Katoliklik mezhebi içerisindeki bir öğreti olan Tommasoculuk'tan kaynaklandığını öne sürmektedir. Ahlaki özellikler içerisinde yer alan akılcı düşünce ve buna bağlı yaşam alanı ve burjuva erdemleri kültürünün oluşturulması öne çıkmaktadır. Sombart ikinci kitapta son olarak toplumsal koşullara odaklanmaktadır. Burada öne çıkan kavramlar devlet başlığı altında Merkantilist devletin kapitalizme hizmet etmesi, eğitim kurumları içerisinde hesap kitap okullarının açılarak ticaret bilgisinin ilerlemesinin sağlanması gibi unsurlardır. Bireysel ya da kolektif göçler yine kapitalizmin oluşmasında temel motiflerden biri olmuştur. Ticaret dışı iş yaşamı kendilerine kapalı olan göçmenler için tek gerçek, gelecek ve para kazanma dürtüsü olmuştur. Diğer bir unsur ise tekniktir. Eskiye özgü teknik, empirik bir özelliğe sahip olup bireysel deneyim etrafında şekillenirken 17. yüzyılda teknik kişisel deneyimin payını azaltarak modern bir yapıya kavuşmuştur ve böylece daha akılcı bir düşünce biçiminin yayılmasını sağlamıştır. Toplumsal koşullar altında kapitalizm öncesi meslekler ile tüccar arasındaki ayrımda kapitalizmin oluşmasındaki temel etkenlerden biridir. Geleneksel toplum içerisinde köylü ya da zanaatkâr malı ile duygusal bir bağ kurarken tüccar malı değiş tokuş nesnesi olarak görerek bu sürecin rasyonalizasyonuna katkıda bulunmuştur.

Sombart, 'Sonuç' bölümünde kapitalist zihniyetin gelişimindeki iki döneme dikkat çekmiştir. Ilk dönem 15. yüzyıl sonuna kadar uzanırken buradaki temel saik töreler, ahlak ve özellikle Hıristiyan ahlakının öğretileridir. íkinci dönem ise 15. yüzyıl sonundan günümüze kadar süregelmiştir. Bu dönemin temel özelliği ise kapitalizmin her türlü engelleme ve kısıtlamadan kurtulmuş olmasıdır.

Werner Sombart, ekonomi bilimini insan ile birlikte alarak bir iktisat tarihçisi ve sosyolog olarak ekonominin evrensel yasalarının olamayacağını tarihsel bir süreç içerisinde konun ele alınması gerektiğini savunmuştur. Bu bağlamda sahip olduğu eleştirel ve bütünsel bakış açısı ile Sombart'ın eserleri hem yaşa-

sürme heveslisidirler buna bağlı olarak Keltlere bağlı bir ırk olan İrlandalılar ekonomi alanında yeteneksizdir yine ticaretin uzun süre art alana atıldığı ve memuriyet yaşamının ön planda tutulduğu Fransa halkını da bu ırk oluşturmaktadır. Kapitalizm konusunda yetenekli olanlar ise genel olarak Etrüskler, Frisonlar ve Yahudiler olarak sıralanabilir. Ayrıntılı bilgi için bkz.: (2017: 225-248).

${ }^{6}$ Bu öğreti yaşama akılcı bir boyut katarak, cinsel iç tepilerin bastırılmasını, savurganlık ve aylaklığın yasaklanmasını ve dürüstlük ilkesini ön plana almıştır. 
dığı dönem için hem de günümüz açısından önemli bir yere sahiptir. ${ }^{7}$ Werner Sombart'ın Burjuva adlı eseri Marcel Mauss'un Armağan başlıklı çalışması ile aynı döneme ait olup benzer kavramlardan bahsetmektedir. Senyör tipi yaşam Mauss'un armağan kültürünü çağrıştırırken akılcı düşünceyi ön plana koyan burjuva yaşam biçimi bunun karşısında bulunmaktadır. ${ }^{8}$ Sombart aynı zamanda Türk akademi camiasında önemli bir yere sahip olan düşünce insanı Sabri F. Ülgener'i etkilemiştir. Klasik iktisat veya faydacı yaklaşım etrafından yalıtılmış bir iktisadi faaliyeti tanımlarken iktisat tarihçisi ve zihniyet problemleri ile ilgilenen Ülgener, Sombart gibi iktisat tarihini kültür tarihi ile yani yaşayan, duyan insan ve onun fikirlerinin toplum nezdindeki somutlaşması olan ideal tipler ile ele alınabileceğini öne sürer. ${ }^{9}$ Bu bakış açısı iktisat tarihi ve zihniyet çalışmaları için ayırt edici bir dönemin başlangıcını ifade etmektedir. Sombart'ın Burjuva adlı eseri kapitalizm, kapitalist zihniyetin oluşum süreçleri ve burjuvazinin iktisadi bir özne olarak tarih içerisinde nasıl ortaya çıktığını ortaya koyması bakımından hâlâ güncel önemini taşısa da, her eser gibi yazıldığı dönem koşulları içerisinde değerlendirilmesi gerekmektedir. Bu açıdan bakıldığında yazarın kapitalist zihniyet, kapitalizm ve burjuvanın belli özellik, nitelik ve eğilimlere sahip etnik gruplar ve ırklarla ortaya çıkabileceği iddiası geçerliliğini yitirmiştir. Çünkü Japonya, Brezilya, Arjantin, Türkiye vb. gibi birçok Batı dışı toplumda kapitalistleşme süreçleri tarih içerisinde gözlemlenmektedir.

\section{Kaynakça}

Mauss, M. (2018). Armağan Üzerine Deneme. (N. Özyıldırım, çev.). İstanbul: Alfa Yayınları.

\footnotetext{
Aşk, Lüks ve Kapitalizm adlı eserinde Sombart kapitalist sistemin gelişmesinde Orta Çağ Avrupası'nda öne çıkan Tanrısal aşk yerine bedensel aşkın yüceltilmesi ve kadınların rolünü tartışmaktadır. Bu dönemdeki prenslerin lüks tüketim ve bedensel aşk peşinde koşması ile kapitalist tüketim düzenin oturması arasında bağlantılar kurmaktadır. Sombart'ın bu eseri ile tüketim toplumu ve postmodern kültür arasında yakın ilişkiler kurmak mümkündür.

${ }^{8}$ Marcel Mauss armağan kültürü ya da potlaç kavramıyla ilkel toplumlar içinde simgesel ve maddi malların değiş tokuş düzenini ortaya koymuştur. Bu düşünce yapısı pazar ilişkilerinin olmadığı bir toplumsal düzende verme ve alma eylemleri üzerine oturan bir karşılıklı yükümlülük ilişkisidir. Ayrıntılı bilgi için bkz.: Armağan Üzerine Deneme ve Sosyoloji ve Antropoloji.

${ }^{9}$ Sabri F. Ülgener iktisadi faaliyeti zihniyet meseleleri ile ele alırken klasik bir dikotomik karşıtlık olan ben ile öteki arasındaki ilişkiye odaklanır. Bu bağlamda Avrupa merkezli rasyonalizm ile Avrupa dışı çevrede yer alan irrasyonalizm arasında dikotomik bir karşıtlık söz konusudur. İktisadi faaliyet bu anlamda içinde yaşanılan toplumun zihinsel yapılanmasından ayгı düşünülemez. Ülgener ve eserleri hakkında ayrıntılı bilgi için bkz.: iktisadi Hayatta Zihniyetin Rolü ve Tezahürleri ve Bir İktisatçının Entelektüel Portresi Sabri F. Ülgener.
} 
-- (2005). Sosyoloji ve Antropoloji. (Ö. Doğan, çev.). Ankara: Doğu Batı Yayınları.

Sombart, W. (2017). Burjuva: Modern Ekonomi Dönemine Ait Insanın Ahlaki ve Entelektüel Tarihine Katkı. (O. Adanır, çev.). Ankara: Doğu Batı Yayınları.

Sayar, A. G. (2007). Bir iktisatçının Entelektüel Portresi Sabri F. Ülgener. İstanbul: Ötüken Neşriyat.

Ülgener, F. S. (1940). “iktisadi Hayatta Zihniyetin Rolü ve Tezahürleri”. Istanbul Üniversitesi iktisat Fakültesi Mecmuası. 2. 351-380. 